\title{
Pengaruh Bauran Pemasaran (Produk, Harga, Tempat dan Promosi) Terhadap Kepuasan Pelanggan Berubah Menjadi Loyalitas Pelanggan Pada Coldplay Juice Soji
}

\author{
The Influence of Marketing Mix (Product, Price, Place, and Promotion) or \\ Customer Statisaction Transform Into Customer Loyality on a Coldplay Juice \\ Soji
}

\author{
Ita Purnamasari ${ }^{*}$, Ratya Anindita ${ }^{2}$, Putri Budi Setyowati ${ }^{2}$ \\ Jurusan Sosial Ekonomi, Fakultas Pertanian, Universitas Brawijaya, Jl. Veteran, Malang (65145)
}

Received: 12 July 2018; Revised: 26 September 2018; Accepted: 27 September 2018

\begin{abstract}
ABSTRAK
Produk minuman Coldplay Juice SOJI merupakan produk minuman yang baru dikalangan konsumen, permasalahan yang terjadi yakni tingkat bertahannya suatu produk baru yang hanya sebentar, dikarenakan kurangnya loyalitas konsumen terhadap suatu produk baru. Pemasaran terkait bauran pemasaran berdasarkan pada kesesuaian konsumen (produk, hraga, tempat dan promosi) berpengaruh terhadap kepuasan pelanggan berubah menjadi loyalitas pelanggan. Tujuan penelitian ini adalah untuk menganalisis tentang pengaruh baurann pemasaran (produk, harga, tempat dan promosi) terhadap kepuasan pelanggan pada Coldplay Juice SOJI dan menganalisis kepuasan pelanggan berubah menjadi loyalitas pelanggan pada Clodplay Juice SOJI. Penelitian menggunakan metode analisis Partial Least Square (PLS), Metode Partial Least Square (PLS) menghasilkan bahwa variabel produk, tempat dan promosi memiliki pengaruh terhadap kepuasan pelanggan dan loyalitas pelanggan dengan nilai p-value kurang dari 0.01 , sedankan untuk variabel harga tidak berpengaruh secara signifikan terhadap kepuasan pelanggan dan loyalitas pelanggan yang ditunjukkan dengan nilai p-value lebih dari 0.05 . R-square pada penelitian ini menunjukkan angka 0.67 pada (Y1) memiliki arti bahwa pengaruh variabel produk, harga, tempat dan promosi terhadap kepuasan pelanggan adalah $67 \%$ dan sisanya $23 \%$ dipengaruhi oleh variabel lain diluar model penelitian ini. R-square pada (Y2) menunjukkan angka 0.57 yang artinya bahwa variabel produk, harga, tempat, promosi dan kepuasan pelanggan adalah 57\% dan 43\% dipengaruhi oleh variabel lain diluar model penelitian ini.
\end{abstract}

Kata kunci: 4p; bauran pemasaran; kepuasan pelanggan; loyalitas pelanggan; coldplay juie SOJI; Partial Least Square (PLS)

\begin{abstract}
Soji Coldplay Juice beverage products is a new beverage products among consumers, problems occurred that the survival rate of a new product only briefly, because of the lack of customer loyalty to a new product. Related marketing marketing mix based on customer suitability (product, hraga, place and promotion) effect on customer satisfaction turns into customer loyalty. The purpose of this study is to analyze the influence baurann of marketing (product, price, place and promotion) of customer satisfaction on Coldplay Juice Soji and analyzing customer satisfaction turns into customer loyalty in Clodplay Juice Soji. Research analysis method Partial Least Square (PLS), Methods of Partial Least Square (PLS) produces that product variables, place and promotion have an influence on customer satisfaction and customer loyalty with a $p$ value less than 0.01, Sedankan to variable rates not significantly affect customer satisfaction and customer loyalty as indicated by the p-value is more than 0.05. R-square of this research showed the 0.67 at (Y1) has the meaning that the effect of variable product, price, place and promotion to customer satisfaction was $67 \%$ and the remaining $23 \%$ is influenced by other variables outside of this research model. $R$-square at (Y2) shows the number 0:57, which means that the variable product, price, place, promotion and customer satisfaction was $57 \%$ and $43 \%$ are influenced by other variables outside of this research model.
\end{abstract}

Keywords: 4p; Marketing Mix; customer satisfaction; customer loyalty; Coldplay Juie Soji; Partial Least Square (PLS) 


\section{How to cite:}

Purnamasari, I., Anindita, R., \& Setyowati, P. B. (2018). Pengaruh Bauran Pemasaran ( Produk , Harga , Tempat dan Promosi ) Terhadap Kepuasan Pelanggan Berubah Menjadi Loyalitas Pelanggan Pada Coldplay Juice Soji. HABITAT, 29(2), 57-64. https://doi.org/10.21776/ub.habitat.2018.029.2.7

\section{Pendahuluan}

Pada era modern sekarang ini, Indonesia merupakan salah satu negara yang sedang berkembang dan memiliki penduduk cukup besar serta bersifat konsumtif. Selain itu, Indonesia merupakan negara dengan pasar potensial bagi pemasaran berbagai jenis produk. Saat ini untuk produk makanan dan minuman telah mengalami perkembangan. Data yang diperoleh Gabungan Perusahaan Makanan dan Minuman Indonesia tahun 2015, pertumbuhan pelaku bisnis makanan dan minuman Nasional tahun 2015 mencapai 8,16 $\%$ bila dibandingkan pada tahun 2014 sebesar 7\% (Husin, 2016).

Bisnis minuman merupakan salah satu bisnis yang mulai berkembang sangat pesat. Munculnya berbagai jenis produk minuman menjadikan persaingan pasar semakin ketat dan membuat produsen saling berlomba untuk memberikan yang terbaik kepada konsumen. Produk minuman tersebut telah dimodifikasi dengan kemasan, rasa, dan harga yang bervariasi. Maka dari itu, suatu perusahaan dituntut untuk dapat memproduksi suatu produk yang berkualitas sehingga konsumen menjadi puas.

Sekarang ini, banyak dijumpai produk minuman dengan berbagai jenis dan merek. Bentuknya beragam, mulai dari bentuk serbuk sampai bentuk cair dan kemasan yang ditampilkan mulai berkembang. Banyak masyarakat yang menyukai makan dan minuman siap saji, konsumen juga memperhatikan kualitas serta bahan-bahan yang digunakan. Saat ini produk minuman cukup disukai oleh masyarakat adalah yang terbuat dari bahan-bahan organik. Salah satu produk minuman saat ini adalah cold play juice. Cold play juice merupakan salah satu produk baru yang memiliki karakteristik produk sangat unik. Dengan model kemasan yang mengikuti era global, rasa dan manfaat produk cold play juice ini sangat unik dan sesuai dengan kebutuhan pasar sekarang.

Bauran pemasaran dianggap sebagai salah satu unsur strategi yang paling potensial didalam memasarkan produk. Strategi bauran pemasaran

"Penulis Korespondensi

E-mail: Itasmanela@gmail.com yaitu : produk, harga, promosi dan tempat sangat berperan terutama pada keadaan persaingan yang semakin tajam dan perkembangan akan permintan barang (Singh, 2012). Keadaan persaingan yang sangat tajam dewasa ini, terutama dalam pasar pembelian, peranan penetapan harga dan promosi penjualan sangart penting terutama untuk membangun komitmen dan loyalitas pelanggan.

Penelitian ini bertujuan memberikan gambaran mengenai pengaruh komponenkomponen bauran pemasaran yang mencangkup produk, harga, promosi dan tempat yang mempengaruhi kepuasan dan loyalitas konsumen terhadap produk minuman cold play juice SOJI di Malang. Kepuasan pelanggan diperlukan bagi kesuksesan bisnis, namun itu saja tidak cukup untuk membangun loyalitas. Pentingnya melakukan penelitian tentang loyalitas dikarenakan, loyalitas pelanggan memiliki kolerasi yang positif dengan performa bisnis perusahaan. Loyalitas tidak hanya meningkatkan nilai dalam bisnis tetapi juga dapat menarik pelanggan baru. Didalam penelitian ini akan dilihat peran bauran pemasaran apa saja yang membuat konsumen tetap memilih produk cold play juice daro SOJI sebagai minuman favoritnya. Oleh karena itu penulis tertarik untuk mengambil judul "Pengaruh Bauran Pemasaran Terhadap Kepuasan Pelanggan Berubah Menjadi Loyalitas Pelanggan pada Produk minuman Cold play Juice SOJI".

\section{Metode Penelitian}

Penelitian dilakukan di SOJI yang berada di Malang Town Square, Kota Malang, Jawa Timur. Penelitian ini dilaksanakan pada bulan Februari 2018 sampai dengan bulan Maret 2018.

Penelitian yang akan dilakukan menggunakan metode survei. Penelitian survei (survey research) adalah bentuk pengumpulan data menggunakan kuesioner yang disebarkan kepada orang atau responden yang melakukan pembelian Coldplay Juice SOJI. Penentuan sampel menggunakan non-probability sampling yang bersifat accidental sampling. Jumlah sampel yang digunakan dalam penelitian sebanyak 100 responden. 


\subsection{Evaluasi Model SEM-PLS}

a. Model Struktural (Struktural Model) atau Pengaruh Variabel Laten Eksogen Terhadap Variabel Laten Endogen

Pada tahap ini dikenal hubungan kausalitas antar variabel yang dibangun berdasarkan teori. Adapun persamaan inner model dalam penelitian ini, yakni:

$\eta_{1}=\gamma_{1} \xi_{1}+\gamma_{2} \xi_{2}+\gamma_{3} \xi_{3}+\gamma_{4} \xi_{4}+\zeta$.

$\eta_{2}=\gamma_{1} \xi_{1}+\gamma_{2} \xi_{2}+\gamma_{3} \xi_{3}+\gamma_{4} \xi_{4}+\eta_{1} \xi_{5}+\zeta$.

Keterangan:

$\eta_{1}=$ konstruk kepuasan pelanggan

$\eta_{2}=$ konstruk loyalitas pelanggan

$\gamma_{1}=$ koefisien konstruk produk

$\gamma_{2}=$ koefisien konstruk harga

$\gamma_{3}=$ koefisien konstruk tempat

$\gamma_{4}=$ koefisien konstruk promosi

$\xi_{1}=$ konstruk produk

$\xi_{2}=$ konstruk harga

$\xi_{3}=$ konstruk tempat

$\xi_{4}=$ konstruk promosi

$\xi_{5}=$ konstruk kepuasan pelanggan

$\zeta=$ galat dalam model

b. Diagram Jalur

Pada tahap selanjutnya setelah mengidentifikasi inner model dan outer model, yakni membuat path atau diagram jalur.

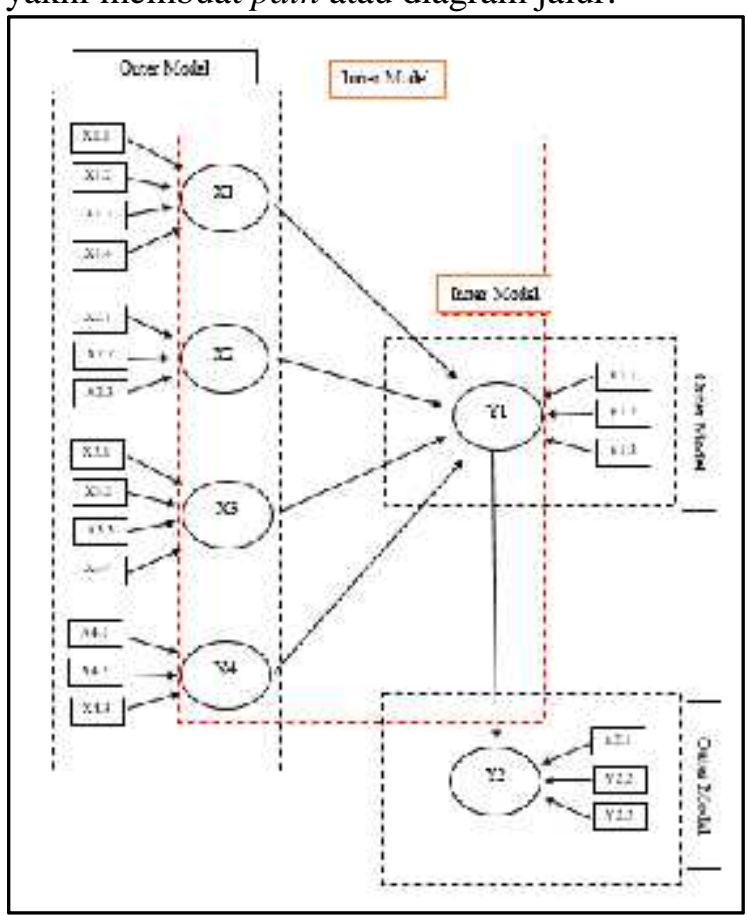

Gambar 1. Diagram Jalur Penelitian

Sumber: Latan dan Ghozali (2017)

Keterangan

X1 : Produk
X1.1 : Variasi produk

X1.2 : Kualitas produk

$\mathrm{X} 1.3$ : Penyajian produk

$\mathrm{X} 1.4$ : Desain produk

X2 : Harga

X2.1 : Harga sesuai dengan kualitas produk

X2.2 : Kepuasan harga yang disepakati

$\mathrm{X} 2.3$ : Diskon

X3 : Tempat

X3.1 : Cangkupan pasar

X3.2 : Persediaan produk

X3.3 : Kebersihan tempat

X3.4 : tampilan outlet

X4 : Promosi

$\mathrm{X} 4.1$ : Pelayanan

X4.2 : Informati E-Market

$\mathrm{X} 4.3$ : Iklan

Y1 : Kepuasan Pelanggan

Y1.1 : Pilihan yang tepat

Y1.2 : Memenuhi harapan pelanggan

Y1.3 : Pemgalaman yang menyenangkan

Y2 : Loyalitas Pelanggan

Y2.1 : Pelanggan tetap membeli produk untuk masa depan

Y2.2 : Merekomendasikan kepada orang lain

Y2.3 : Berniat untuk memberikan saran dan ide-ide untuk perkembangan produk

c. Evaluasi Model Pengukuran atau Pengaruh Indikator Terhadap Variabel Laten

Pada pembentukan dan operasionalisasi suatu konstruk dapat dibentuk dengan indikator refleksif dan formatif. Evaluasi model pengukuran dengan konstruk berbentuk refleksif terdiri dari beberapa tahap yakni mengevaluasi nilai indicator reliability, Internal consistency reliability, Convergent Validity dan Discriminant Validity. Ukuran yang digunakan untuk mengukur reliabilitas indikator dapat dianalisa dengan melihat nilai loading factor $>0.7$, nilai loading factor menunjukkan nilai indikator untuk menjelaskan konstruk laten. Evaluasi yang kedua yakni dengan melihat Internal Consistency Reliability dengan pengukuran nilai composite reliability. Model dinyatakan reliable jika nilai composite reliability $>0.7$ (Latan dan Ghozali, 2017)

Evaluasi yang ketiga yakni validitas konvergen (Convergent validity) dan Evaluasi keempat yakni validitas diskriminan (Discriminant validity). Nilai AVE pada validitas konvergen harus menunjukkan nilai lebih besar dari 0,5. Nilai ini menggambarkan validitas konvergen yang memadai dan mempunyai arti 
bahwa satu variabel laten mampu menjelaskan lebih dari setengah varian dari indikatorindikatornya dalam rata-rata. Pada validitas diskriminan membandingkan nilai Square Root of Average Variance Extracted (AVE) setiap konstruk dengan korelasi antar konstruk lainnya dalam model, jika Square Root Of Average Variance Extracted (AVE) konstruk lebih besar dari korelasi dengan seluruh konstruk lainnya maka dikatakan memiliki discriminant validity yang baik. Direkomendasikan nilai pengukuran harus lebih besar dari 0,50.

d. Evaluasi Model Struktural atau Pengaruh Variabel Laten Eksogen Terhadap Variabel Laten Endogen

Analisa inner model merupakan model structural yang dilakukan untuk memprediksi hubungan antar kausalitas variable laten atau hipotesis dalam penelitian. Analisa inner model dapat dilihat dari koefision determinasi $\left(R^{2}\right.$ atau $\mathrm{R}$ square) dan predictive relevance ( $Q$-square atau $\mathrm{Q}^{2}$ ). Kriteria nilai $\mathrm{R}^{2}$ terdiri dari tiga kriteria, yaitu $\mathrm{R}^{2}$ 0.67, 0.33, dan 0.19 sebagai substansi, moderat, dan lemah. Sementara kriteria $\mathrm{Q}^{2}$ terdiri dari dua kriteria, yaitu $\mathrm{Q}^{2}>0$ menunjukkan bahwa model mempunyai predictive relevance dan $\mathrm{Q}^{2}<0$ menunjukkan bahwa model kurang memiliki predictive relevance.

Langkah terakhir dari analisis data yakni melakukan pengujian hipotesis dengan menggunakan metode resampling stable 3 . Statistik uji yang digunakan dalam penelitian ini adalah statik $\mathrm{t}$ dengan hipotesis sebagai berikut:

Hipotesis statistik untuk outer model untuk pengaruh indikator terhadap variabel laten adalah:

$\mathrm{H} 0=\lambda \mathrm{i}=0$

$\mathrm{H} 1=\lambda \mathrm{i} \neq 0$

Hipotesis statistik untuk inner model untuk pengaruh variabel laten eksogen terhadap variabel laten endogen adalah:

$\mathrm{H} 0=\gamma \mathrm{i}=0$

$\mathrm{H} 1=\gamma \mathrm{i} \neq 0$

Pengujian dilakukan dengan menggunakan ttest, apabila diperoleh nilai p-value $\leq 0,05$ (alpha $5 \%$, maka nilai tersebut signifikan sehingga menolak $\mathrm{H} 0$ dan menerima $\mathrm{H} 1$ sehingga hipotesis diterima.

\section{Hasil dan Pembahasan}

\subsection{Gambaran Umum Objek Penelitian}

Produk minuman Coldplay Juice SOJI bermula dari bisnis keluarga yang dirintis pada 04 Desember 2016. Awal Desember 2016, masih belum memiliki outlet untuk tempat jualan, pengenalan produk ini masih dengan media sosial dan media cetak. Produk minuman Coldplay Juice SOJI merupakan produk minuman yang tebuat dari beberapa buah segar dan sayuran, pembuatannya dengan cara di mix sesuai dengan porsi dan rasa serta manafat untuk kesehatan. Produk minuman ini hanya bertahan lima hari karena tidak menggunakan bahan pengawet dan masih memperhatikan kesegaran dalam pembuatan coldplay juice SOJI. Seseuai dengan manfaat produk, coldplay juice SOJI memiliki arti di kata "SOJI" yaitu sebuah singkatan yang berbunyi "Sehat Nomor Siji".

\subsection{Pengaruh Bauran Pemasaran Terhadap Keputusan Pembelian}

\subsubsection{Pengaruh Indikator Terhadap Variabel Laten}

Model Pengukuran Reflektif

Langkah pertama yakni melihat Indicator Reliability pada parameter Loading Factor. Nilai loading factor setiap indikator lebih dari 0,7 . Nilai p-value pada setiap indikator juga menunjukkan nilai kurang dari 0,05 . Hal tersebut menunjukkan bahwa indikator yang digunakan memenuhi syarat atau aturan dari kriteria yang telah ditentukan.

Langkah kedua yakni melihat internal consistency reliability melalui parameter composite reliability, nilai composite reliability menunjukkan nilai 0,07 yang berarti memenuhi syarat composite reliability. Hal tersebut menunjukkan setiap variabel konsisten dalam mengukur konstruk.

Langkah ketiga yakni melihat Convergen Validity melalui paramater Average Variance Extracted (AVE). Nilai dari Average Variance Extracted lebih dari 0,5 yang berarti menunjukkan nilai AVE baik dan memenuhi validitas konvergen. Langkah berikutnya yakni dengan melihat Full collin. VIF dengan syarat harus menunjukkan nilai kurang dari 3,3. Nilai Full collin. VIF sebesar 2,612 yang berarti tidak adak ada masalah kolinearitas dalam model.

Langkah keempat yakni melihat Diskriminant Validity. Membandingkan cross loading dengan indicator loading. Hasil menunjukkan nilai cross loading yang melebihi nilai indicator loading, sehingga dapat dikatakan bawa indikator tersebut valid.

Melihat Diskriminant Validity melalui parameter akar kuadrat AVE dan korelasi antar konstruk laten dengan syarat akar kuadrat AVE harus lebih besar daripada korelasi antar konstruk 
laten. Pada tabel 1 nilai akar kuadrat AVE ditunjukkan pada nilai yang berada didalam kurung.

Tabel 1. Correlation Among Lateng Variable and Square Roots of AVEs

\begin{tabular}{ccccccc}
\hline & $\mathrm{X} 1$ & $\mathrm{X} 2$ & $\mathrm{X} 3$ & $\mathrm{X} 4$ & $\mathrm{Y} 1$ & $\mathrm{Y} 2$ \\
\hline $\mathrm{X} 1$ & $\mathbf{( 0 . 7 8 6 )}$ & 0.585 & 0.686 & 0.581 & 0.719 & 0.631 \\
$\mathrm{X} 2$ & 0.585 & $\mathbf{( 0 . 8 0 3 )}$ & 0.720 & 0.438 & 0.575 & 0.506 \\
$\mathrm{X} 3$ & 0.686 & 0.720 & $\mathbf{( 0 . 8 1 2 )}$ & 0.611 & 0.689 & 0.695 \\
$\mathrm{X} 4$ & 0.581 & 0.438 & 0.611 & $\mathbf{( 0 . 7 6 4 )}$ & 0.684 & 0.630 \\
$\mathrm{Y} 1$ & 0.719 & 0.575 & 0.689 & 0.684 & $\mathbf{( 0 . 8 5 1 )}$ & 0.754 \\
$\mathrm{Y} 2$ & 0.631 & 0.506 & 0.695 & 0.630 & 0.754 & $\mathbf{( 0 . 8 1 8 )}$ \\
\hline
\end{tabular}

\subsubsection{Pengaruh Variabel Laten Eksogen} Terhadap Variabel Laten Endogen

a. Estimate for Path Coefficients

Pada Koefisien jalur (Estimate for Path Coefficients) menunjukkan adanya hubungan atau pengaruh tidaknya antar konstruk. Variabel X1, $\mathrm{X} 3$, dan X4 terhadap Y1 berpengaruh secara nyata dengan nilai koefisien jalur masing-masing 0.38 , 0.17 , dan 0.30 dan signifikan pada p-value $<0,01$. Variabel harga atau X2 yang menunjukkan nilai koefisien jalur yang tidak berpengaruh nyata terhadap kepuasan pelanggan atau Y1 yang ditunjukkan nilai p-value lebih dari 0,05 . Variabel Y1 terhadap Y2 atau Loyalitas pelanggan berpengaruh nyata dengan nilai koefisien jalur 0.76 dan signifikan ada $p$-value $<0.01$.

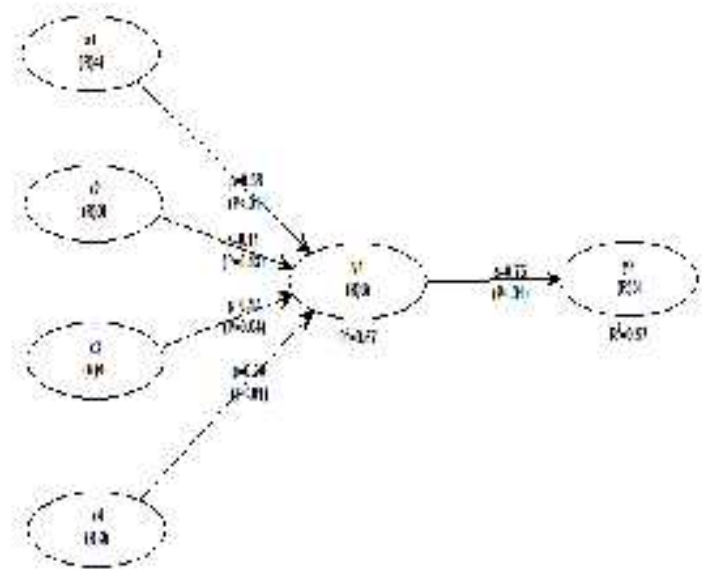

Gambar 2. Diagram Estimate for Path Coefficients

b. R-square

$R$-square ditunjukkan pada variabel $\mathrm{Y} 1$ yang menunjukkan nilai $\mathrm{R}^{2}$ sebesar 0,67 pada gambar 1. hal tersebut dapat diartikan bahwa adanya kontribusi variabel produk (X1), harga (X2), tempat (X3) dan promosi (X4) terhadap kepuasan pelanggan sebesar 67\% dan sisanya 33\% dipengaruhi oleh variabel lain yang tidak dilakukan dalam penelitian ini. variabel Y2 yang menunjukkan nilai $\mathrm{R}^{2}$ sebesar 0,57 pada gambar 1 . hal tersebut dapat diartikan bahwa adanya kontribusi variabel kepuasan pelanggan (Y1) terhadap loyalitas pelanggan sebesar 57\% dan sisanya $43 \%$ dipengaruhi oleh variabel lain yang tidak dilakukan dalam penelitian ini.

c. APC, ARS dan AVIF

Pada evaluasi inner model pada evaluasi terakhir dilakukan evaluasi pada APC, ARS dan AVIF yang merupakan indikator bagian dari goodnes of fit model. Nilai fit yang cukup baik dimana nilai dari Average Path Cofficient (APC) sebesar 0,3433 dan $\mathrm{P}<0.001$, nilai Average $R$ Squared (ARS) 0,621 dengan nilai $\mathrm{p}<0,001$ dan nilai Average block VIF (AVIF) sebesar 2,237 yang menunjukkan nilai kurang dari 3,3, hal ini menunjukkan bahwa tidak ada masalah multikolonieritas antar indikator dan antar variabel eksogen. Goodness of fit (GoF) yang dihasilkan dalam penelitian ini menunjukkan nilai 0,635 yang berarti fit model termasuk dalam kategori besar dan layak karena lebih dari 0.36 .

Tabel 4. Nilai Average Path Cofficient (APC), Average $R$-Squared (ARS), Average block VIF (AVIF) dan Goodness of fit (GoF)

\begin{tabular}{lcc}
\hline & Nilai & $\mathrm{p}$-value \\
\hline $\begin{array}{l}\text { AveragePath Cofficient } \\
\text { (APC) }\end{array}$ & 0.342 & $<0.001$ \\
$\begin{array}{l}\text { AverageR-Squared (ARS) } \\
\text { Average block VIF (AVIF) }\end{array}$ & 0.621 & $<0.001$ \\
Goodness of fit (GoF) & 0.635 & \\
\hline
\end{tabular}

3.3. Pembahasasan Terkait Pengaruh Produk, Harga, Tempat dan Promosi Terhadap Kepuasan Pelanggan Berubah Menjadi Loyalitas pelanggan

\subsubsection{Pengaruh Produk Terhadap Kepuasan Pelanggan pada Minuman Coldplay Juice SOJI}

Hipotesis pertama menunjukkan bahwa adanya produk berpengaruh terhadap Kepuasan Pelanggan. Hal ini ditunjukkan dengan nilai pvalue kurang dari 0.01. Adapun syarat dikatakan signifikan atau memiliki pengaruh yakni apabila suatu variabel memiliki p-value kurang dari 0.05. Variabel produk juga memiliki koefisien jalur sebesar 0.38, dari hasil data yang diperoleh menunjukkan bahwa hipotesis pertama diterima yakni dengan terima Ha dan tolak Ho.

Hasil dari penelitian ini sejalan dengan hasil penelitian Ramadhan (2015) yang menunjukkan 
bahwa penyajian produk pada suatu produk berpengaruh positif dan signifikan terhadap kepuasan oleh pelanggan. Pengaruh positif menunjukkan bahwa semakin baik penyajian produk yang ditawarkan maka semakin besar tingkat kepuasan pelanggan dalam membeli dan mengkonsumsi produk. Sesuai dengan Kotler dan Amstrong (2008:266) yang mendefinisikan produk sebagai segala sesuatu yang dapat ditawarkan kepada pasar agar menarik perhatian, penggunaan atau konsumsi yang dapat memuaskan suatu keinginan atau kebutuhan.

\subsubsection{Pengaruh Harga Terhadap Kepuasan Pelanggan pada Minuman Coldplay Juice SOJI}

Hasil penelitian menunjukkan bahwa adanya variabel harga tidak berpengaruh signifikan terhadap keputusan pembelian. Hal ini ditunjukkan dengan nilai dari p-value melebihi syarat signifikan yakni sebesar 0.13 , yang berarti terima Ho dan tolak Ha dengan koefisien jalur sebesar 0.11. Kotler dan Amstrong (2008:63) menyatakan bahwa harga adalah sejumlah uang yang harus dibayarkan pelanggan untuk memperoleh produk.

Variabel harga juga menunjukkan hasil yang tidak signifikan namun positif pada penelitian Baryn Sacaksana (2016) menunjukkan bahwa variabel harga mempunyai pengaruh positif dan signifikan terhadap kepuasan pelanggan. Maka dari itu pada penelitian menunjukkan bahwasannya harga tidak memiliki pengaruh pada kepuasan pelanggan karena pelanggan merasakan kualitas dan manfaat yang diperoleh sehingga memungkinkan harga tidak memiliki pengaruh..

\subsubsection{Pengaruh Tempat Terhadap Kepuasan Pelanggan pada Minuman Coldplay Juice SOJI}

Tempat pada penelitian ini terdiri dari empat indikator, yakni kemudahan pasar, persediaan produk, kebersihan lokasi dan tempat penjualan. Variabel tempat ini menghasilkkan koefisien jalur sebesar 0.17 dengan p-value sebesar 0.04 yang memenuhi syarat untuk dinyatakan signifikan atau memiliki pengaruh terhadap kepuasan pelanggan. Hasil data yang diperoleh menunjukkan bahwa hipotesis ketiga diterima.

Hasil dari penelitian ini selaras dengan penelitian yang dikemukakan oleh Afrida Shela Mavita (2013) yang menyatakan bahwa variabel tempat berpengaruh signifikan terhadap kepuasan pelanggan. Penelitian mengungkapkan fakta bahwa responden memperhatikan tempat sebagai pertimbangan pembelian. Menurut hasil observasi peneliti, tempat berpengaruh signifikan karena konsumen rata-rata telah memiliki kendaraan pribadi yang memungkinkan konsumen bisa berbelanja kapan pun dan dimana pun dan terdapat sistem penjualan online yang dapat membantu konsumen menikmati produk minuman coldplay juice SOJI apabila outlite penjualan produk dikatan jauh oleh pelanggan.

\subsubsection{Pengaruh Promosi Terhadap Kepuasan Pelanggan pada Minuman Coldplay Juice SOJI}

Promosi merupakan bagian dari bauran pemasaran yang memiliki pengaruh terhadap kepuasan pelanggan. Ditunjukkan dengan koefisien jalur sebesar 0.30 dan p-value kurang dari 0.01. Menurut Kotler dan Armstrong (2008:63) menyatakan bahwa promosi adalah aktivitas yang menyampaikan manfaat produk dan membujuk pelanggan agar membelinya.

Berdasarkan analisa lapang, konsumen lebih tertarik membeli dan puas dikarenakan terpengaruhnya konsumen terhadap iklan pada media sosial yang dilakukan produk minuman coldplay juie SOJI, kemudian tersedianya informasi yang lengkap terkait produk pada media sosial dan media cetak mengakibatkan konsumen tertarik untuk membeli dan merasakan kepuasan dari informasi produk yang didapatkan.

\subsubsection{Pengaruh Kepuasan Pelanggan Berubah Menjadi Loyalitas Pelanggan}

Kepuasan pelanggan dalam penelitian ini memiliki tiga indikator yakni pilihan yang tepat, memenuhi harapan pelanggan dan pengalaman yang menyenangkan. Variabel kepuasan pelanggan menghasilkan koefisien jalur 0.76 dan p-value kurang dari 0.01. Mnurut Lovelock dan Wirtz (2011) kepuasan adalah sikap yang diputuskan berdasarkan pengalaman yang didapatkan.

Pada analisis dilapang, pelanggan lebih puas dan loyal terhadap produk yang sesuai dengan harapan konsumen. Karena sesuai dengan tujuan produk yaitu dapat memenuhi kebutuhan pelanggan dan bermanaat untuk pelanggan. Penelitian ini menunnjukkan bahwa kepuasan pelanggan berpengaruh dan signifikan terhadap loyalitas pelanggan, sesuai dengan penelitian Fajar (2013) yang menjelaskan bahwa kepuasan pelanggan memiliki pengaruh besar terhadap loyalitas pelanggan karena pelaggan merasakan pengalaman yang menyenangkan, pelanggan 
memiliki rasa perhatian produk dengan memberikan saran-saran positif pada produk dan menjadi pelanggan tetap untuk masa yang akan datang.

\section{Kesimpulan}

Pengaruh bauran pemasaran (produk, harga, tempat dan promosi) menunjukkan hubungan yang positif terhadap kepuasan pelanggan, namun tidak semua variabel dalam bauran pemasaran menunjukkan hasil yang signifikan terhadap kepuasan pelanggan. Hal tersebut ditunjukkan pada path coefficients pada variabel produk, tempat dan promosi yang menunjukkan pengaruh signifikan terhadap kepuasan pelanggan. Variabel produk menunjukkan hasil signifikan sebesar 0.38 dan pvalue kurang dari 0.01 , ariabel tempat juga menunjukkan hasil signifikan sebesar 0.17, variabel promosi menunjukkan hasil signifikan sebesar 0.30 dan p-value kurang dari 0.01. Berbeda dengan variabel harga menunjukkan hasil p-value lebih dari 0.05 yang menunjukkan tidak signifikannya terhadap kepuasan pelanggan karena hasil yang ditunjukkan dengan p-value masing-masing yakni sebesar 0.13. Variabel kepuasan pelanggan memiliki pengaruh besar terhadap loyalitas pelanggan dengan nilai koefisien jalur sebesar 0.76 dan p-value kuran dari 0.01 .

Saran yang dapat diberikan dalam penelitian ini setelah menerapkan metode SEM PLS adalah sebagai berikut:

Minuman Coldplay Juice SOJI hendaknya terus meningkatkan inovasi produk maupun memperbaiki perkembangan kualitas produk. Inovasi produk bisa dilakukan baik dari sisi ukuran kemasan dan kualitas produk bisa dilakukan dari segi varian rasa pada produk minuman coldplay juice SOJI. Adanya perkembangan inovasi rasa baru bisa diterapkan pada produk, karena sesuatu yang baru akan menimbulkan rasa penasaran pada diri konsumen.

Promosi pada produk minuman coldplay juice SOJI bisa ditambah melalui kegiatan promosi intens pada kegiatan-kegiatan atau acara yang dilakukan di daerah bisnis. Produk juga sebaiknya dapat di toko-toko pembelanjaan, hal tersebut agar produk yang baru ini dapat dikenal oleh masyarakat dan dapat dijadikan prioritas pembelian.

Pada penelitian ini hanya menggunakan bauran pemasan $4 \mathrm{P}$ yang terdiri dari product, price, place, dan promotion. Maka dari itu, peneliti memberikan saran agar pada penelitian selanjutnya menggunakan $7 \mathrm{P}$ yang terdiri dari product, price, place, promotion, process, physical evidence, dan people ataupun penggunaan variabel lainnya yang dapat mempengaruhi kepuasan pelanggan berubah menjadi loyalitas pelanggan. Penggunaan variabel tersebut diharapkan agar peneliti mendapatkan hasil yang lebih baik, dan dapat menunjukkan variabel mana saja yang berpengaruh besar dalam mempengaruhi.

\section{Daftar Pustaka}

Afrinda, S. (2013). Pengaruh Bauran Pemasaran Terhadap Kepuasan Konsumen. Jurnal Ilmu dan Riset Managemen, Vol 2, 2-18.

Bryan, S. (2016). Pengaruh Bauran Pemasaran (Marketing Mix) Terhadap Loyalitas Konsumen Produk Fanta PT Coca-Cola Amatil Indonesia di Kota Semarang. Jurnal Managemen dan Bisnis Indonesia, 1-12.

Fajar. (2012). Analisis Pengaruh Kepuasan Terhadap Loyalitas Konsumen. Jurnal Managemen dan Bisnis Indonesia.

Hair. et.al. (1997). Multivariate Data Analysis With Reading (Edisi 4 ed.). New Jersey: Prentice Hall.

Hasan, A. (2008). Marketing. Yogjakarta: Media Utama.

Husin. (2016). Data Gabungan Perusahaan Makanan dan Minuman. Jurnal Managemen.

Kotler Philip dan Gary Amstrong. (2004). Dasardasar Pemasaran edisi kesembilan. New Jersey: Prantice Hall.

Kotler, \& Amstrong. (2007). Dasar-dasar Pemasaran. England: Alih Bahasa Alexander Ltd.

Kotler, P. (2002). Marketing Managemen. Upper Saddle River, N.J: Prentice Hall.

Kotler, P. d. (2006). Principal of Marketing. Pearson Prentice Hall: Pearson Education.

Kotler, P. d. (2008). Manaemen Pemasaran. Jakarta: Erlangga.

Kotler, P., \& Keller, K. (2004). Pemasaran Pengolaan. New Jersey: Perason Education, Inc. 
Kotler, Philip. (2013). Manajemen Pemasaran. Edisi Kesebelas. Jilid 1 dan 2. Jakarta : PT Indeks hal 98

Lovelock, W. (2011). Managemen Pemasaran. Jakarta: PT. INDEKS.

Lumintan, D. (2015). The Impact of Marketing Mix towards Customer Loyality Mediated by Customer Satisfaction of Blackberry Indonesia. iBuss Managemen, Vol. 3, 316324.

Manapo, F. (2013, Desember 14). Kualitas Pelayanan, dan Servicecape Pengaruhnya Terhadap Kepuasan. Jurna IMBA , 13411348.

Putu, Y. (2016). Pengaruh Bauran Pemasaran Terhadap Kepuasan dan Loyalitas Pelanggan Produk. Jurnal Managemen dan Pelayanan Farmasi, 115-122.

Putu, Y. (2016). Pengaruh Bauran Pemasaran Terhadap Kepuasan dan Loyalitas Pelanggan Produk. Jurnal Manajemen dan Pelayanan Farmasi, p-ISSN:2088-8139, 115-122.

Ramadhan. (2015). Analisis Loyalitas Konsumen terhadap Minuman Kopi di Kota Banda Aceh. Jurnal Managemen.

Schiffman. (2008). Perilaku Konsumen. Jakarta: PT. INDEKS.

Shiffman, \& Kanuk. (2008). Perilaku Konsumen. Jakarta: PT. INDEKS.

Singh, M. (2012). Marketing Mix of 4P'S for Competitive Advantage. IOSR Journal of Business and Management (IOSRJBM), 3, 40-45.

Sugiono. (2010). Metode Penelitian Bisnis. Bandung: Alfabeth.

Sugiyono. (2010). Metode Penelitian Binis. Bandung: Alfabeth.

Tjiptono, F. (2008). Strategi Pemasaran (Edisi Kedua ed.). Malang: Penerbit Bayu Media Malang.

Vannesa, G. (2007). Customer Relationship Managemen and Marketing Public Relation. Bandung: Alfabeth. 